\title{
Improving the metallic content of focused electron beam-induced deposits by a scanning electron microscope integrated hydrogen-argon microplasma generator
}

\author{
Hiroyuki Miyazoe ${ }^{\text {a) }}$ \\ Laboratory for Mechanics of Materials and Nanostructures, Swiss Federal Laboratories for Materials \\ Testing and Research-EMPA, Feuerwerkerstrasse 39, CH-3602 Thun, Switzerland \\ and Department of Advanced Materials Science, Graduate School of Frontier Sciences, \\ The University of Tokyo, 5-1-5 Kashiwanoha, Kashiwa-shi, Chiba 277-8561, Japan \\ Ivo Utke \\ Laboratory for Mechanics of Materials and Nanostructures, Swiss Federal Laboratories for Materials \\ Testing and Research-EMPA, Feuerwerkerstrasse 39, CH-3602 Thun, Switzerland \\ Hirokazu Kikuchi and Shinya Kiriu \\ Laboratory for Mechanics of Materials and Nanostructures, Swiss Federal Laboratories for Materials \\ Testing and Research-EMPA, Feuerwerkerstrasse 39, CH-3602 Thun, Switzerland \\ and Department of Advanced Materials Science, Graduate School of Frontier Sciences, \\ The University of Tokyo, 5-1-5 Kashiwanoha, Kashiwa-shi, Chiba 277-8561, Japan \\ Vinzenz Friedli and Johann Michler \\ Laboratory for Mechanics of Materials and Nanostructures, Swiss Federal Laboratories for Materials \\ Testing and Research-EMPA, Feuerwerkerstrasse 39, CH-3602 Thun, Switzerland
}

Kazuo Terashima

Department of Advanced Materials Science, Graduate School of Frontier Sciences, The University of Tokyo, 5-1-5 Kashiwanoha, Kashiwa-shi, Chiba 277-8561, Japan

(Received 20 October 2009; accepted 17 May 2010; published 6 July 2010)

Local coinjection of a $\left(\mathrm{H}_{2}-\mathrm{Ar}\right)$ microplasma jet and $\mathrm{Cu}\left(\mathrm{O}_{2} \mathrm{C}_{5} \mathrm{~F}_{6} \mathrm{H}\right)_{2}$ molecules during focused electron beam-induced deposition (FEBID) was studied with respect to changes in the $\mathrm{Cu}: \mathrm{C}$ ratio of deposits. Microplasma-assisted FEBID (30 keV and $1 \mathrm{nA}$ ) decreased codeposition of carbon, oxygen, and fluorine originating from the chamber background and the precursor molecule. The copper metal content could be increased to 41 at. \%, being almost four times more than in conventional FEBID deposits without coinjection. Conventional FEB deposits from $\mathrm{Cu}\left(\mathrm{O}_{2} \mathrm{C}_{5} \mathrm{~F}_{6} \mathrm{H}\right)_{2}$ resulted in 11-12 at. \% $\mathrm{Cu}$ content. Microplasma post-treatments of conventional FEB deposits resulted in volume changes, surface roughening, and an increase of the overall $\mathrm{Cu}$ content to 27 at. $\%$. The removal mechanisms were of nonthermal nature. At repulsive bias potentials from 0 to $+30 \mathrm{~V}$, a pure chemical etching of the carbonaceous matrix by atomic hydrogen radials occurred. At attractive bias potentials of up to $-30 \mathrm{~V}$, a more efficient ion induced chemical sputtering regime prevailed where $\mathrm{Ar}^{+}$ions break carbon bonds, which in turn will be passivated by atomic hydrogen radicals to form volatile hydrocarbon compounds. (c) 2010 American Vacuum Society.

[DOI: $10.1116 / 1.3449808]$

\section{INTRODUCTION}

Maskless focused electron beam-induced processing (FEBIP) such as etching and deposition has been intensively investigated in the last few decades. ${ }^{1-3}$ This technique allows to direct assemble various types of materials for nanoscale prototyping of electrical, optical, and magnetic elements, as well as structuring complex three-dimensional (3D) structures. In FEBIP, a precursor vapor molecule, being adsorbed on a substrate surface, is dissociated under irradiation of the focused electron beam (FEB). According to the choice of precursor molecules, the electron-impact dissociation products can form nonvolatile deposits or react further to volatile compounds with the substrate. Recently, $20 \mathrm{~nm}$ sized holes,

${ }^{a)}$ Electronic mail: miyazoe@terra.mm.t.u-tokyo.ac.jp corresponding to $20 \%$ of the beam size employed, were achieved for $\mathrm{H}_{2} \mathrm{O}$ FEB etching of a carbon membrane. ${ }^{4}$ For $\mathrm{W}(\mathrm{CO})_{6}$ FEB deposition, nanodots measuring approximately $1 \mathrm{~nm}$ in size were obtained ${ }^{5}$ on a membrane. High spatial resolution of FEB deposition was also demonstrated for 3D nanostructuring by fabricating freestanding carbon nanopillars with a thickness of $5 \mathrm{~nm}$. $^{6}$

Many metal-containing molecules have been employed in focused electron beam-induced deposition (FEBID) and their compositions have been investigated. ${ }^{2,3}$ One of the pertinent challenges is to deposit high-metallic-content material. Generally, metal organic precursors are used as precursors and nonthermal dissociation by electron impact results in metallic nanocrystals embedded in an amorphous carbonaceous matrix. ${ }^{7,8}$ The nature of the carbonaceous matrix was studied with FEB deposits obtained from organic molecules by Bret 
et $a{ }^{9}{ }^{9}$ in high-vacuum systems: the composition was estimated to be close to the sum formula $\mathrm{C}_{9} \mathrm{H}_{2} \mathrm{O}_{1}$ independent of the organic molecule, and the carbon was more than $90 \%$ $s p^{2}$-bonded and approximately $2 \mathrm{~nm}$ in nanocrystalline size. The amount of such codeposited carbonaceous material can be somewhat reduced by controlling the beam current, ${ }^{8,10}$ by substrate heating during ${ }^{11,12}$ and after $^{13}$ deposition, by coinjection of reactive gases such as water, ${ }^{14-18}$ by using an inorganic precursors, ${ }^{19-21}$ and by using ultrahigh-vacuum chambers in combination with specific surfaces. ${ }^{22-24}$ The above methods proved successful for a few molecules but failed for molecules with a high thermal decomposition temperature and large carbon content, such as $\mathrm{Cu}\left(\mathrm{O}_{2} \mathrm{C}_{5} \mathrm{~F}_{6} \mathrm{H}\right)_{2}$ and $\left(\mathrm{CH}_{3}\right)_{3} \mathrm{Pt}-\mathrm{CpCH}_{3}$. In addition, many metals, such as copper, silver, nickel, and silicon, to name a few, are very prone to oxidation that excludes many reactive gases for carbon removal.

An alternative approach to reduce the carbon-deposited material without oxidizing the metal consists in applying chemically reactive atomic hydrogen treatment that removes carbon via chemical reduction. Post-treatment of conventional FEB platinum-carbon deposits from $\left(\mathrm{CH}_{3}\right)_{3} \mathrm{Pt}-\mathrm{CpCH}_{3}$ was studied by Botman et al.: ${ }^{12}$ irradiation with atomic hydrogen generated by the hot filament method resulted in a dense, 30-nm-thick, carbon-free, Pt surface layer (below this layer the deposit remained unaffected). The overall electrical resistivity of the post-treated material was reduced to $(2.2 \pm 0.7) \times 10^{4} \mu \Omega \mathrm{cm}$, which was 1000 times lower than that of nontreated FEB deposits.

Especially, copper has been widely used due to its lower cost and lower electrical resistivity. Luisier et al. ${ }^{25}$ indicated that planar $\mathrm{Cu}$ containing deposits fabricated by conventional FEBID with $\mathrm{Cu}\left(\mathrm{O}_{2} \mathrm{C}_{5} \mathrm{~F}_{6} \mathrm{H}\right)_{2}$ molecules in high-vacuum microscopes showed electrical characteristics similar to insulator materials and $\mathrm{Cu}: \mathrm{C}: \mathrm{O}$ ratio of 14:75:5.

In this article, we propose a scanning electron microscope (SEM)-integrated microplasma generator for chemically active hydrogen such as free radicals and ions to reduce the carbonaceous matrix in FEB deposits without oxidizing its metal content. The combination of electron beam and plasma technology has been widely investigated for gas-laser applications ${ }^{26-28}$ and material processings. ${ }^{29,30}$ Furthermore, the combination of a plasma from "nanonozzle" with an atomic force microscopy (AFM) system was also reported: etch pits and lines into $\mathrm{Si}$ with a full width at half maximum of $270 \mathrm{~nm}$ using $\mathrm{O}_{2}-\mathrm{SF}_{6}$ plasma jet supplied via a focused ion beam (FIB)-fabricated nanonozzle could be obtained. ${ }^{31}$ Microplasmas have attracted much attention due to their energy and cost savings, ${ }^{32,33}$ in addition to the highly reactive characteristics. The successful integration of a low-power driven microplasma source into a SEM without any disturbance of the precise electron beam focus and position was demonstrated in Ref. 34. In the following, its efficient use as a SEM-integrated hydrogen plasma source for coinjection during conventional FEBID and as post-treatment will be explained.

\section{EXPERIMENTAL PROCEDURE}

\section{A. General remarks}

Two approaches for hydrogen $\left(\mathrm{H}_{2}\right)$-argon (Ar) microplasma were investigated in this work. First, a microplasma post-treatment, applied after the conventional FEBID process, and second, "microplasma-assisted FEBID" was performed, meaning the coinjection of the plasma during the FEBID process. A high vacuum SEM (S3600N, Hitachi) with a tungsten cathode was used for FEBID. Micron-sized structures were fabricated to examine the metallic content in the deposits by microanalysis. A lithography system (Xedraw2, Xenos Semiconductor Technologies $\mathrm{GmbH}$ ) was used to control the position and dwell time of the electron beam focused on the substrate. The current of the primary electron beam (probe current) was measured by a picoammeter (Model 6485, Keithley Instruments Inc.) and fixed to the desired value. The microscope chamber was pumped down to the background pressure of $10^{-4} \mathrm{~Pa}$ by an oil diffusion pump, supported by an oil rotary pump for rough pumping. The pressure during the process was measured by a cold cathode gauge (PTR225, Oerlikon Leybold Vacuum). The molecule $\mathrm{Cu}\left(\mathrm{O}_{2} \mathrm{C}_{5} \mathrm{~F}_{6} \mathrm{H}\right)_{2} \cdot x \mathrm{H}_{2} \mathrm{O}$ known as $\mathrm{Cu}(\mathrm{II})$ hexafluoroacetylacetonate hydrate or $\mathrm{Cu}(\mathrm{hfa})_{2} \cdot x \mathrm{H}_{2} \mathrm{O}$ was obtained from Sigma-Aldrich Co. and dehydrated for over 1 $h$ in the vacuum of the microscope chamber (which turned its color from green to gray). Then, deposition was performed using $\mathrm{Cu}\left(\mathrm{O}_{2} \mathrm{C}_{5} \mathrm{~F}_{6} \mathrm{H}\right)_{2}$ as a precursor molecule. Naturally oxidized silicon was used as a substrate, cleaned by ethylacetate in an ultrasonic bath, and rinsed with isopropanol. A laboratory made gas injection system was used to direct the precursor vapor to the substrates. The inner nozzle diameter was $600 \mu \mathrm{m}$ and supplied a molecule flux of $\sim 10^{17} \mathrm{~cm}^{-2} \mathrm{~s}^{-1}$ to the substrate area where FEB irradiation took place. The position of the nozzle tip was controlled with a precision of smaller than $5 \mu \mathrm{m}$ in situ under SEM observation. To reduce the unwanted codeposition from the residual hydrocarbons in the microscope chamber, a liquid nitrogen trap was installed around the sample holder.

The microplasma system was described elsewhere in detail. $^{34}$ Its main specifications comprise a plasma torch consisting of a five-turn solenoid coil, a tungsten (W) wire (diameter: $100 \mu \mathrm{m}$ ), and a fine quartz capillary (inner diameter $500 \mu \mathrm{m}$ ) with a tapered nozzle (final inner diameter of $100 \mu \mathrm{m}$, fabricated using a commercial micropipette puller P-2000, Sutter Instrument). An ultrahigh frequency (450 $\mathrm{MHz}$ ) power source (Nihon Koshuha) was connected to the inductive coil to sustain the microplasma and to heat the $\mathrm{W}$ wire for the emission of thermoelectrons. A high directcurrent voltage $(15 \mathrm{kV}$ for $0.6 \mathrm{~s})$ was applied to the $\mathrm{W}$ wire to ignite the plasma. The total pressure in the region of plasma generation within the quartz capillary was estimated to be between 1 and $3 \mathrm{kPa}$ by a simple calculation based on fluid dynamics. ${ }^{34}$ This was close to the pressure range reported by Geddes et al. ${ }^{35}$ who measured a $\mathrm{H}_{2}$ dissociation efficiency of about $90 \%$ resulting from the balance of atom production and loss mechanisms at a pressure of $4 \mathrm{kPa}$ in a 
(a)

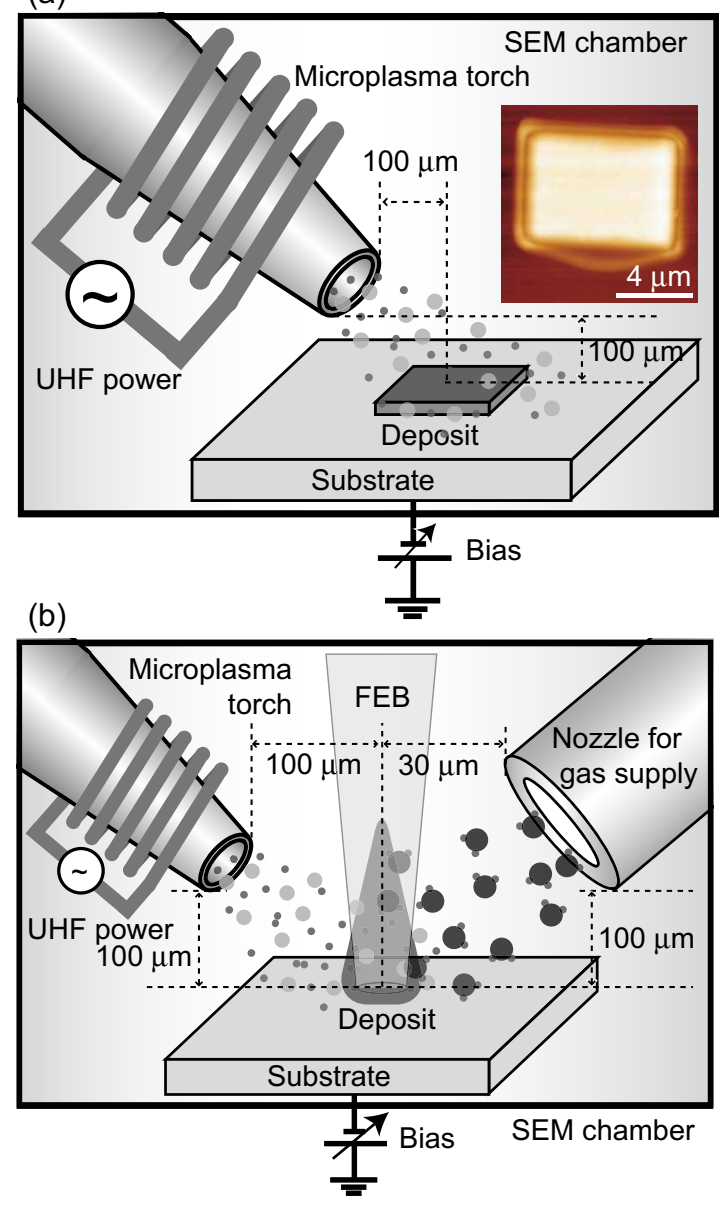

TABLE I. Experimental conditions for microplasma post-treatment. The unit sccm stands for cubic centimeter per minute.

\begin{tabular}{|c|c|}
\hline \multicolumn{2}{|l|}{ Parameter for FEBID } \\
\hline Energy of primary electron $(\mathrm{keV})$ & 5 \\
\hline Probe current $(\mathrm{pA})$ & 1000 \\
\hline Flow rate of precursor molecule (molecules $/ \mathrm{cm}^{-2} \mathrm{~s}$ ) & $3.0 \times 10^{17}$ \\
\hline \multicolumn{2}{|l|}{ Parameter for microplasma } \\
\hline Flow rate of $\mathrm{Ar}(\mathrm{sccm})$ & 0.98 \\
\hline Flow rate of $\mathrm{H}_{2}(\mathrm{sccm})$ & $0-0.28$ \\
\hline Input power $(\mathrm{W})$ & $5-13$ \\
\hline Bias on substrate $(\mathrm{V})$ & -30 to +20 \\
\hline Treatment time (min) & $0-60$ \\
\hline Chamber Pressure $(\mathrm{Pa})$ & $\sim 1.0 \times 10^{-1}$ \\
\hline
\end{tabular}

plasma post-treatment of FEB deposits by $\mathrm{H}_{2}-\mathrm{Ar}$ microplasma was carried out inside the SEM. The scheme of the experimental setup is illustrated in Fig. 1(a). The plasma torch nozzle was located $100 \mu \mathrm{m}$ away from the center of the deposits at an angle of approximately $35^{\circ}$. In order to avoid any effect of the direct-current voltage pulse used for plasma ignition $(15 \mathrm{kV}, 0.6 \mathrm{~s})$, the sample stage was moved approximately $20 \mathrm{~mm}$ away while the plasma was ignited. Then, the Ar plasma was generated and $\mathrm{H}_{2}$ gas was admixed. The plasma and the position of the plasma torch became stable after approximately $10 \mathrm{~min}$. Next, the sample stage was moved back to close position and irradiation with the $\mathrm{H}_{2}-\mathrm{Ar}$ microplasma was performed. During irradiation, the generation and sustenance of the plasma were confirmed by an infrared camera installed in the SEM chamber. The plasma irradiation time, the flow rate of $\mathrm{H}_{2}$, and the bias potential of the substrate were varied. The detailed conditions for microplasma post-treatment are summarized in Table I.

\section{Microplasma-assisted FEBID}

The experimental setup of in situ $\mathrm{H}_{2}-\mathrm{Ar}$ microplasmaassisted FEBID is schematically illustrated in Fig. 1(b). The position of the plasma torch tip was $100 \mu \mathrm{m}$ away from the point of electron beam incidence on the substrate and similar to the setup shown in Fig. 1(a). To avoid charging, the tip of the quartz capillary used for the plasma torch was coated with a $6.5 \mathrm{~nm}$ thick chromium layer and a $200 \mathrm{~nm}$ thick gold layer and grounded. To obtain an intense $\mathrm{Cu}\left(\mathrm{O}_{2} \mathrm{C}_{5} \mathrm{~F}_{6} \mathrm{H}\right)_{2}$ molecule flux, the position of the nozzle for the precursor supply was fixed at $30 \mu \mathrm{m}$ close to the position irradiated by the FEB. The primary electron energy was fixed at $30 \mathrm{keV}$ and the probe current was $1.0 \mathrm{nA}$ for all experiments. The FEB was continuously spotted on the same position for some tens of minutes. The applied bias potential on the substrate and the flow rate of plasma gases such as $\mathrm{Ar}$ and $\mathrm{H}_{2}$ were varied as experimental parameters, see Table II. 
TABLE II. Experimental conditions for microplasma-assisted FEBID.

\begin{tabular}{|c|c|}
\hline \multicolumn{2}{|l|}{ Parameter for FEBID } \\
\hline Energy of primary electron (keV) & 30 \\
\hline Probe current $(\mathrm{pA})$ & 1000 \\
\hline Flow rate of precursor molecule (molecules $/ \mathrm{cm}^{-2} \mathrm{~s}$ ) & $3.0 \times 10^{17}$ \\
\hline \multicolumn{2}{|l|}{ Parameter for microplasma } \\
\hline Flow rate of $\mathrm{Ar}(\mathrm{sccm})$ & $0.14-0.98$ \\
\hline Flow rate of $\mathrm{H}_{2}(\mathrm{sccm})$ & $0.07-0.14$ \\
\hline Input power $(\mathrm{W})$ & 12 \\
\hline Bias on substrate (V) & -30 to +30 \\
\hline
\end{tabular}

\section{RESULTS AND DISCUSSION}

\section{A. Microplasma post-treatment}

Surfaces of as-prepared $\mathrm{Cu}$ containing planar FEB deposits were very flat as observed by the SEM and AFM characterizations. The compositions were $\mathrm{Cu} 11 \pm 1.2$ at. \%, $\mathrm{C} 62 \pm 2.1$ at. \%, O $21 \pm 2.9$ at. \%, and F $6 \pm 2.5$ at. $\%$. After plasma irradiation, the surface of the deposits became rough and grains with sizes ranging approximately from 30 to $100 \mathrm{~nm}$ were observed. The root mean square surface roughness values of deposits increased from 1.0 to $4.7 \mathrm{~nm}$ with increasing irradiation time (up to $60 \mathrm{~min}$ ). The height of the FEB deposits decreased almost proportionally from $160 \pm 5$ to $100 \pm 5 \mathrm{~nm}$. Furthermore, the roughness became more significant with increasing flow rate of $\mathrm{H}_{2}$ gas [0-0.28 SCCM (SCCM denotes cubic centimeter per minute at STP)] and with increasing negative bias potential $(0$ to $-30 \mathrm{~V})$. Without applying a bias potential, the atomic concentration of $\mathrm{Cu}$ increased from 11 to 27 at. \% after $60 \mathrm{~min}$ of $\mathrm{H}_{2}-\mathrm{Ar}$ microplasma irradiation, as plotted in Fig. 2.

Simultaneously, the $\mathrm{C}$ content in the deposit decreased from 62 to 41 at. \%, whereas the $\mathrm{O}$ and $\mathrm{F}$ contents did not change remarkably; they stayed at approximately 20 and 6

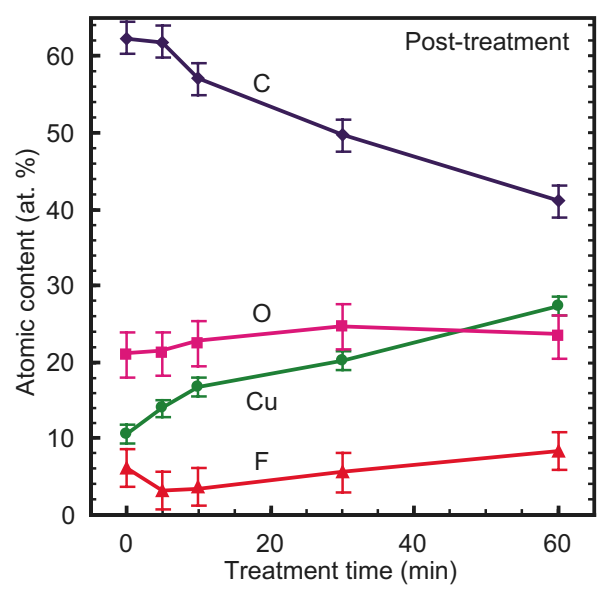

FIG. 2. (Color online) EDXS measured composition of the deposits as a function of irradiation time. (Flow rate of $\mathrm{H}_{2}=0.21 \mathrm{SCCM}$, input power $=12 \mathrm{~W}$, and applied bias on substrate $=0 \mathrm{~V}$.) Treatment time $t=0$ min corresponds to an as-prepared FEB deposit $(5 \mathrm{keV}, 1 \mathrm{nA})$ from $\mathrm{Cu}\left(\mathrm{O}_{2} \mathrm{C}_{5} \mathrm{~F}_{6} \mathrm{H}\right)_{2}$ precursor.

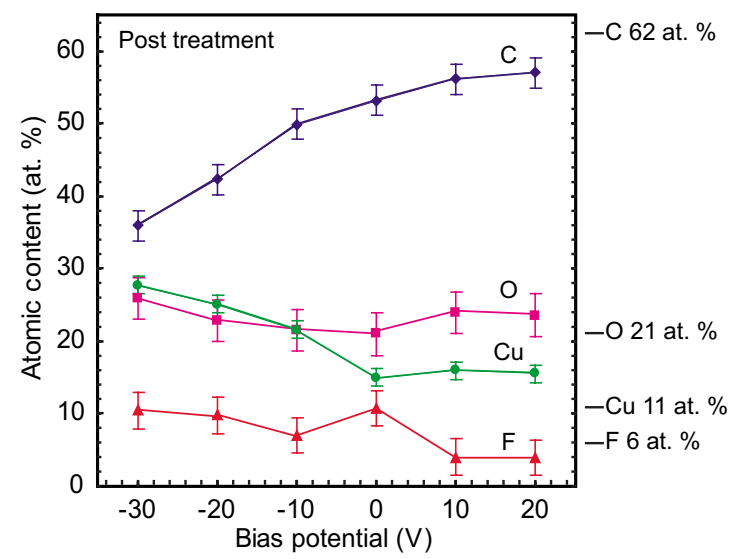

FIG. 3. (Color online) Composition of the FEB deposits after $\mathrm{H}_{2}-\mathrm{Ar}$ microplasma postirradiation for $30 \mathrm{~min}$ as a function of applied bias potential on the substrate (flow rate of $\mathrm{H}_{2}=0.14 \mathrm{SCCM}$, input power= $12 \mathrm{~W}$ ). The right axis indicates the atomic contents of $\mathrm{Cu}, \mathrm{C}, \mathrm{O}$, and $\mathrm{F}$ in the as-prepared FEB deposits from $\mathrm{Cu}\left(\mathrm{O}_{2} \mathrm{C}_{5} \mathrm{~F}_{6} \mathrm{H}\right)_{2}$.

at. \%, respectively. Of note is that the above EDXS measured composition values contain information from different depths, see Sec. II. However, depth profiling with Auger electron spectroscopy could not resolve a metal-rich (plasma-treated) surface layer as was found in Ref. 12, probably due to the surface roughness involved. Most importantly, a contamination of tungsten from the $\mathrm{W}$ wire used for plasma generation inside plasma torch was not observed. Irradiation with pure Ar microplasma did not result in any noticeable changes in morphology and composition of the FEB deposits. This result assures that (a) no thermal annealing effects were involved in all our plasma treatments and that (b) one can surely attribute the decrease in carbonaceous content to a chemical reaction by which the hydrogen radicals (and, much less dominantly as we will see below, $\mathrm{H}^{+}$ ions) form volatile products with the carbonaceous matrix.

A bias voltage from -30 to $+20 \mathrm{~V}$ was applied to the substrate to study the effect of low landing energy of plasma ions. Figure 3 shows the EDXS measured composition of the microstructure as a function of substrate bias potential after $\mathrm{H}_{2}-\mathrm{Ar}$ microplasma irradiation for $30 \mathrm{~min}$. The best reduction in carbon content was achieved with our largest negative $(-30 \mathrm{~V})$ bias potential: the atomic content of $\mathrm{C}$ reduced to 36 at. \% and that of $\mathrm{Cu}$ increased to 27 at. \%, which is more than double of the conventional FEBID-Cu content. The contents of $\mathrm{O}$ and $\mathrm{F}$ stay constant within the error margins.

When applying a positive bias potential, compositional changes with respect to zero bias stayed within the error margins for the elements $\mathrm{Cu}$ (slightly increasing), $\mathrm{C}$ (slightly decreasing), and $\mathrm{O}$ (slightly increasing); only $\mathrm{F}$ decreased significantly from 10 down to 4 at. \%. Obviously, the repulsive positive substrate potential rejects all the positive $\mathrm{H}^{+}$ and $\mathrm{Ar}^{+}$ions of the plasma, leaving only the neutral atomic $\mathrm{H}$ radicals for the chemical etch reaction with the carbonaceous matrix. Since the copper and carbon content changed only insignificantly from 0 to $+20 \mathrm{~V}$ repulsive potential, it can be concluded that neutral atomic hydrogen radical constitutes the dominant reactive species of hydrogen in the 


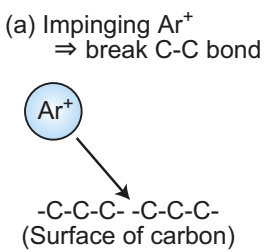

(b) Impinging $\mathrm{H}^{*}$ $\Rightarrow$ passivate C-

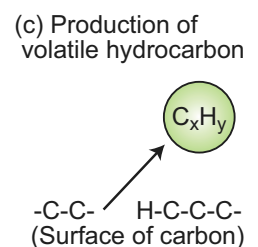

FIG. 4. (Color online) Schematic principle of ion induced chemical sputtering for $\mathrm{H}_{2}-\mathrm{Ar}$ microplasma irradiation on samples with an attractive bias potential.

plasma. When applying an attractive negative potential of a few tens of $\mathrm{eV}, \mathrm{Ar}^{+}$and $\mathrm{H}^{+}$ions impinge on the FEB deposit with a kinetic energy not sufficient enough to physically sputter atoms, however, enough to cause intermixing and bond breakage within the surface region, which should greatly enhance the reaction with the coimpinging atomic hydrogen. Intermixing, bond breakage, and consequent molecule rearrangements can be accessed via complex molecular dynamics simulations. ${ }^{40}$ The most possible mechanism of the observed enhanced carbon removal in our experiments seems that the accelerated $\mathrm{Ar}^{+}$ions physically break $\mathrm{C}-\mathrm{C}$ bonds within their penetration range of a few angstroms and that the dangling bonds become readily chemically passivated by the coimpinging atomic $\mathrm{H}$ radicals from the plasma to form volatile hydrocarbon products, see Fig. 4. This mechanism is similar to the ion induced chemical sputtering proposed in Ref. 41.

\section{B. Microplasma-assisted FEBID}

\section{Shape of deposits}

A SEM-integrated microplasma generator requires effective shielding of electromagnetic field when operated simultaneously with the focused electron since the paths of the primary and the secondary electrons will be affected.

Figure 5(a) shows the SEM image of a FEB-deposited dot obtained with a shielding system, which used a metal tube to protect the path of the primary electron beam. Without shielding, the path of primary electron beam was deflected by the oscillating electromagnetic field and the resulting deposit showed ellipsoidal shape, although the FEB was stationary spotted at the center of the ellipse, see Fig. 5(b). The area of the ellipse was approximately proportional to the power supplied into plasma generating coil. Figures 5(c) and 5(d) show the SEM images of FEB-dot deposits with and without $\mathrm{H}_{2}-$ Ar plasma assistance, respectively. No bias was applied on the substrate in both cases. For better comparison, the deposit shown in Fig. 5(d) was fabricated under $\mathrm{H}_{2}-\mathrm{Ar}$ molecule flow with the same flow rates $(\mathrm{Ar}=0.14$ SCCM and $\mathrm{H}_{2}=0.07$ SCCM) as those used for the plasma assisted deposits presented in Fig. 5(c). Both experiments result in a conical shape deposit with similar base diameter of approximately $1.5 \mu \mathrm{m}$. On the other hand, the deposits shown in Figs. 5(c) and 5(d) were fabricated in 90 and 20 min, respectively. Assuming axially symmetric deposit shapes, the growth rates were approximately 4000 and $13000 \mathrm{~nm}^{3} / \mathrm{min}$,
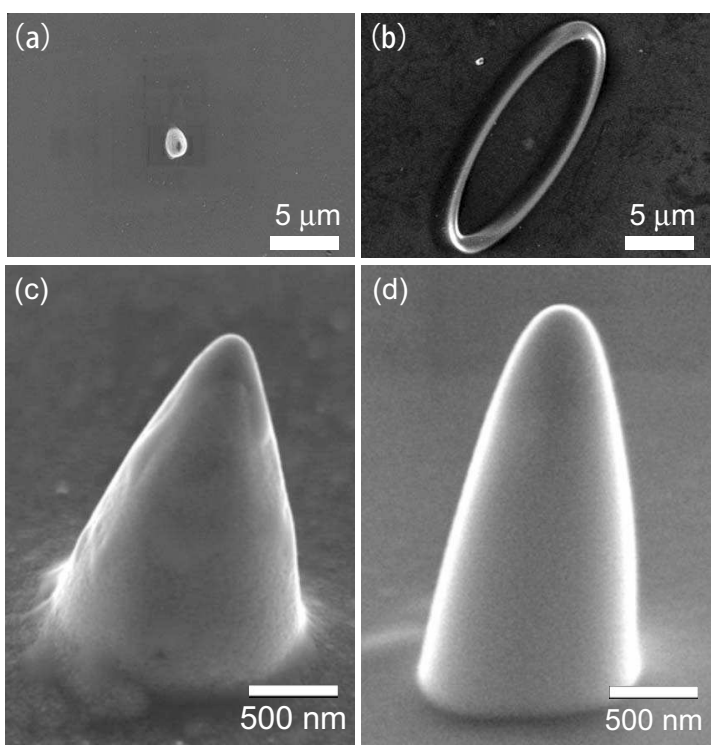

FIG. 5. SEM images of microplasma-assisted FEB deposits. Top view of deposits (a) with and (b) without shielding of the electromagnetic field. $60^{\circ}$ tilt images of dot deposits fabricated (c) by microplasma-assisted FEBID and (d) by conventional FEBID process.

respectively; i.e., the rate of microplasma-assisted FEBID was about $31 \%$ of the unassisted deposition.

As for microplasma post-treatments, a bias potential was applied to the substrate from -30 to $30 \mathrm{~V}$, see Figs. 6(a) and 6(b). The height of the deposits did not vary significantly with bias. However, upon applying a negative voltage at -30 $\mathrm{V}$, the shape of the conical deposit became slightly sharper than that deposited at $+30 \mathrm{~V}$ bias.

\section{Halo deposits}

A FIB milled cross section of a microplasma-assisted FEB deposit is shown in Fig. 7(a). Around the conical shape deposit, a thin radial halo deposit with a thickness of approximately $230 \mathrm{~nm}$ is observed. The lateral extension of the halo deposit is some hundreds of micrometers, as can be seen from an optical microscope image taken with white light in Fig. 7(b). The change in interference colors indicates that the thickness of the halo decreases radially with distance from the center. We performed gas flux simulations based on an algorithm described in Ref. 42 and with the geometries and arrangements of the plasma torch and the molecule nozzle shown in Fig. 7(b). It turns out that the halo deposit is
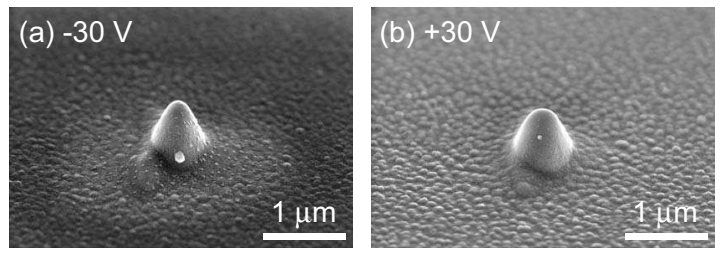

FIG. 6. $60^{\circ}$ tilt SEM images of microplasma-assisted FEB dot deposits (exposure $30 \mathrm{~min}, 30 \mathrm{keV}, 1 \mathrm{nA}$ ) fabricated with substrate bias potentials of (a) $-30 \mathrm{~V}$ and $(\mathrm{b})+30 \mathrm{~V}$. The flow rates were of $\mathrm{Ar}=0.14 \mathrm{SCCM}$ and $\mathrm{H}_{2}$ $=0.07 \mathrm{SCCM}$; the input power was $12 \mathrm{~W}$. 

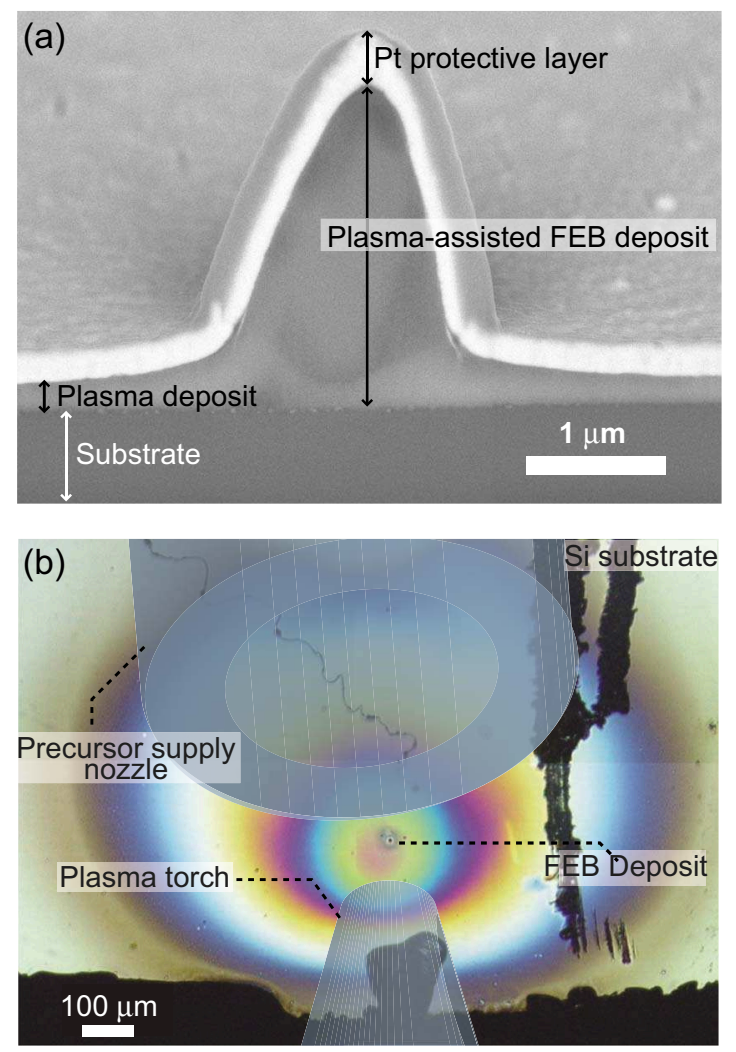

FIG. 7. (Color online) (a) Cross sectional SEM image of a microplasmaassisted FEB dot deposit fabricated in $90 \mathrm{~min}$ and (b) top view optical microscope image of the radial halo deposit showing interference colors due to thickness variations. The position of the plasma torch and the gas injection nozzle are indicated.

formed via dissociation of surface adsorbed molecules by the impinging reactive plasma. Interestingly, the halo deposition rate increased threefold at an applied bias of $-30 \mathrm{~V}$; obviously the adsorbate molecules were subject to the same chemical sputtering process as discussed above, which led to the simultaneous deposition a nonvolatile copper containing fragment being inert to hydrogen chemistry. Evidently, such nonlocal, large-area halo deposition is undesirable for FEBID prototyping. However, it can be principally avoided by toggling the plasma jet and the molecule jet. In our present setup such a procedure could not be implemented.

\section{Composition}

Figure 8 shows the composition of plasma-assisted FEBdots deposited during $30 \mathrm{~min}\left(\mathrm{Ar}=0.14 \mathrm{SCCM}\right.$ and $\mathrm{H}_{2}$ $=0.07 \mathrm{SCCM}$ ). $\mathrm{H}_{2}-$ Ar plasma assisted FEB deposition results in higher metallic contents for negative bias potentials. The $\mathrm{Cu}$ content increased from 25 to 41 at. \% when changing the substrate bias from +30 to $-30 \mathrm{~V}$, while that of contamination, such as $\mathrm{C}$ and $\mathrm{O}$ decreased from 53 to 45 at. \% and from 20 to 13 at. \%, respectively. In particular, the F content became undetectable.

Relating the volume deposition rates and the $\mathrm{Cu}$ contents of the plasma assisted and nonassisted dot deposits shown in Figs. 5(c) and 5(d) gives a value very close to one: $(4000: 13000) / 41: 12)=1.05$. This suggests that the disso-

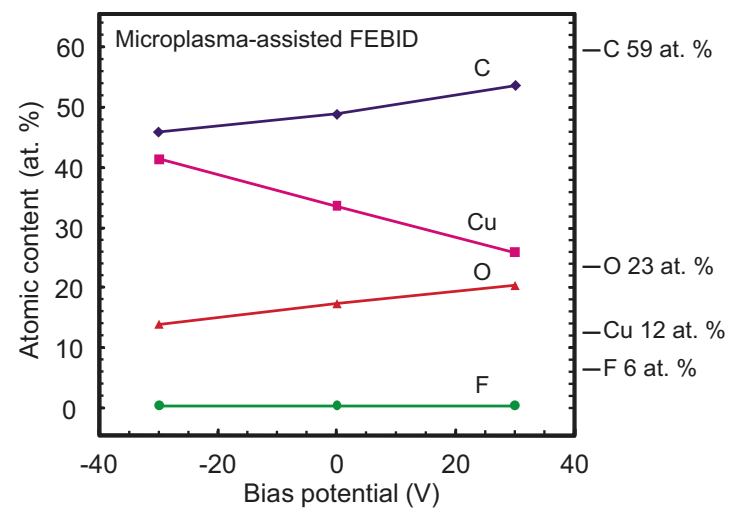

FIG. 8. (Color online) Composition of the microplasma-assisted FEB deposits as a function of applied bias on the substrate. The right axis indicates the atomic contents of $\mathrm{Cu}, \mathrm{C}, \mathrm{O}$, and $\mathrm{F}$ in as-prepared deposits from $\mathrm{Cu}\left(\mathrm{O}_{2} \mathrm{C}_{5} \mathrm{~F}_{6} \mathrm{H}\right)_{2}$ obtained under similar FEB exposure conditions.

ciation of adsorbed molecules within the electron irradiated area predominantly proceeds via electron impact, while the coinjected $\mathrm{H}_{2}-\mathrm{Ar}$ plasma jet in its turn etches the FEB codeposited carbonaceous matrix to finally give a metal-rich deposit. No significant influence was observed in the composition when the plasma gas flow was more than 0.7 SCCM in total. Such a high metal content was not yet reported for FEBID with this molecule and clearly shows the high potential of our microplasma-assisted approach.

\section{CONCLUSION}

$\mathrm{H}_{2}-\mathrm{Ar}$ microplasma assisted focused electron beaminduced deposition with $\mathrm{Cu}\left(\mathrm{O}_{2} \mathrm{C}_{5} \mathrm{~F}_{6} \mathrm{H}\right)_{2}$ was examined in order to obtain deposits structures with metallic contents higher than about 10 at. \% normally obtained by the conventional FEBID method. $\mathrm{H}_{2}-\mathrm{Ar}$ microplasma post-treatment selectively removed the carbon from the surface of the prefabricated FEB deposits. In contrast, a homogeneous increase in metallic content was obtained with in situ $\mathrm{H}_{2}-\mathrm{Ar}$ microplasma assistance during FEBID. All other codeposited elements from the precursor molecule decreased in content. Furthermore, compared to the plasma post-treatment, the surface of the fabricated deposit was smooth and no surface damage was observed. Although both cases require further studies on optimizations of processes in order to obtain pure metals or to understand the process mechanisms in detail, the above results prove the great potential of coinjection of a reducing reactive gas for FEBID of purer metal material.

Moreover, plasma can supply other chemically activated atoms such as nitrogen, carbon, and oxygen. By coinjecting such highly reactive species to the conventional metal deposition process, the fabrication of compounds such as carbides, nitrides, and oxides might become possible as already presented for macromaterial processes. ${ }^{30,43}$

\section{ACKNOWLEDGMENT}

One of the authors (H.M.) thanks financial support from a Research Grant-in Aid for JSPS fellows from the Japan Society for the Promotion of Science (JSPS). 
${ }^{1}$ S. J. Randolph, J. D. Fowlkes, and P. D. Rack, Crit. Rev. Solid State Mater. Sci. 31, 55 (2006).

${ }^{2}$ I. Utke, P. Hoffmann, and J. Melngailis, J. Vac. Sci. Technol. B 26, 1197 (2008).

${ }^{3}$ A. Botman, J. J. L. Mulders, and C. W. Hagen, Nanotechnology 20, 372001 (2009).

${ }^{4}$ H. Miyazoe, I. Utke, J. Michler, and K. Terashima, Appl. Phys. Lett. 92, 043124 (2008).

${ }^{5}$ W. F. van Dorp, B. van Someren, C. W. Hagen, and P. Kruit, Nano Lett. 5, 1303 (2005).

${ }^{6}$ J. Fujita, M. Ishida, T. Ichihashi, Y. Ochiai, T. Kaito, and S. Matsui, J. Vac. Sci. Technol. B 21, 2990 (2003).

${ }^{7}$ C. Schössler, J. Urban, and H. W. P. Koops, J. Vac. Sci. Technol. B 15, 1535 (1997)

${ }^{8}$ I. Utke, T. Bret, D. Laub, P. Buffat, L. Scandella, and P. Hoffmann, Microelectron. Eng. 73-74, 553 (2004).

${ }^{9}$ T. Bret, S. Mauron, I. Utke, and P. Hoffmann, Microelectron. Eng. 78-79, 300 (2005).

${ }^{10}$ I. Utke, J. Michler, P. Gasser, C. Santschi, D. Laub, M. Cantoni, P. A. Buffat, C. Jiao, and P. Hoffmann, Adv. Eng. Mater. 7, 323 (2005).

${ }^{11}$ M. Weber, H. W. P. Koops, M. Rudolph, J. Kretz, and G. Schmidt, J. Vac. Sci. Technol. B 13, 1364 (1995).

${ }^{12}$ A. Botman, M. Hesselberth, and J. J. L. Mulders, Microelectron. Eng. 85, 1139 (2008).

${ }^{13}$ A. Botman, J. J. L. Mulders, R. Weemaes, and S. Mentink, Nanotechnology 17, 3779 (2006).

${ }^{14}$ K. Mølhave, D. N. Madsen, A. M. Rasmussen, A. Carlsson, C. C. Appel, M. Brorson, C. J. H. Jacobsen, and P. Boggild, Nano Lett. 3, 1499 (2003).

${ }^{15}$ D. N. Madsen, K. Molhave, R. Mateiu, A. M. Rasmussen, M. Brorson, C. J. H. Jacobsen, and P. Boggild, Nano Lett. 3, 47 (2003).

${ }^{16}$ K. Mølhave, D. N. Madsen, S. Dohn, and P. Boggild, Nanotechnology 15, 1047 (2004).

${ }^{17}$ A. Folch, J. Tejada, C. H. Peters, and M. S. Wrighton, Appl. Phys. Lett. 66, 2080 (1995).

${ }^{18}$ A. Folch, J. Servat, J. Esteve, J. Tejada, and M. Seco, J. Vac. Sci. Technol. B 14, 2609 (1996).

${ }^{19}$ I. Utke, P. Hoffmann, B. Dwir, K. Leifer, E. Kapon, and P. Doppelt, J. Vac. Sci. Technol. B 18, 3168 (2000).

${ }^{20}$ J. D. Barry, M. Ervin, J. Molstad, A. Wickenden, T. Brintlinger, P. Hoffman, and J. Meingailis, J. Vac. Sci. Technol. B 24, 3165 (2006).

${ }^{21}$ A. Perentes, G. Sinicco, G. Boero, B. Dwir, and P. Hoffmann, J. Vac. Sci.
Technol. B 25, 2228 (2007).

${ }^{22}$ I. Utke, A. Luisier, P. Hoffmann, D. Laub, and P. A. Buffat, Appl. Phys. Lett. 81, 3245 (2002).

${ }^{23}$ Y. Kakefuda, Y. Yamashita, K. Mukai, and J. Yoshinobu, Surf. Sci. 601, 5108 (2007).

${ }^{24}$ T. Lukasczyk, M. Schirmer, H. P. Steinruck, and H. Marbach, Small 4, 841 (2008).

${ }^{25}$ A. Luisier, I. Utke, T. Bret, F. Cicoira, R. Hauert, S. W. Rhee, P. Doppelt, and P. Hoffmann, J. Electrochem. Soc. 151, C535 (2004).

${ }^{26}$ R. L. Carlson et al., IEEE J. Quantum Electron. 17, 1662 (1981).

${ }^{27}$ R. A. Gerber, E. L. Patterson, L. S. Blair, and N. R. Greiner, Appl. Phys. Lett. 25, 281 (1974).

${ }^{28}$ C. B. Edwards, F. Oneill, and M. J. Shaw, Appl. Phys. Lett. 38, 843 (1981).

${ }^{29}$ M. Ryoji, T. Hara, K. Ohnishi, M. Hamagaki, Y. Dake, M. Tohkai, and Y. Aoyagi, Jpn. J. Appl. Phys., Part 2 31, 4357 (1992).

${ }^{30}$ T. Aida, A. Tsukamoto, K. Imagawa, T. Fukazawa, S. Saito, K. Shindo, K. Takagi, and K. Miyauchi, Jpn. J. Appl. Phys., Part 2 28, L635 (1989).

${ }^{31}$ J. Voigt, F. Shi, K. Edinger, P. Güthner, and I. W. Rangelow, Microelectron. Eng. 57-58, 1035 (2001).

${ }^{32}$ K. Tachibana, IEEJ Trans., Electr. Electron. Eng. 1, 145 (2006).

${ }^{33}$ A. C. Bose, Y. Shimizu, D. Mariotti, T. Sasaki, K. Terashima, and N. Koshizaki, Nanotechnology 17, 5976 (2006).

${ }^{34}$ H. Miyazoe, M. Sai, S. Stauss, and K. Terashima, J. Vac. Sci. Technol. A 27, 9 (2009).

${ }^{35}$ J. Geddes, R. W. McCullough, A. Donnelly, and H. B. Gilbody, Plasma Sources Sci. Technol. 2, 93 (1993).

${ }^{36}$ L. Reimer, M. Kassens, and L. Wiese, Microchim. Acta [Suppl.] 13, 485 (1996).

${ }^{37}$ R. Yamada, J. Nucl. Mater. 145-147, 359 (1987).

${ }^{38}$ E. Vietzke, V. Philipps, K. Flaskamp, P. Koidl, and C. Wild, Surf. Coat. Technol. 47, 156 (1991).

${ }^{39}$ E. Vietzke, K. Flaskamp, V. Philipps, G. Esser, P. Wienhold, and J. Winter, J. Nucl. Mater. 145-147, 443 (1987).

${ }^{40}$ T. Aoki, S. Chiba, J. Matsuo, I. Yamada, and J. P. Biersack, Nucl. Instrum. Methods Phys. Res. B 180, 312 (2001).

${ }^{41}$ C. Hopf, A. von Keudell, and W. Jacob, J. Appl. Phys. 94, 2373 (2003).

${ }^{42}$ V. Friedli, C. Santschi, J. Michler, P. Hoffmann, and I. Utke, Appl. Phys. Lett. 90, 053106 (2007).

${ }^{43}$ Z. Sitar, M. J. Paisley, D. K. Smith, and R. F. Davis, Rev. Sci. Instrum. 61, 2407 (1990). 